\title{
A divergência na academia: estratégias discursivas de proteção e de preservação das imagens sociais (face-work)
}

\author{
Verbena Lúcia de Medeiros Costa \\ Universidade Estadual do Ceará \\ verbenacosta@yahoo.com.br
}

\section{Resumo}

Nosso objetivo, neste estudo ${ }^{1}$, é investigar as estratégias linguísticas que os docentes usam na Universidade para mitigarem suas divergências, atingirem seus interesses acadêmico-científicos e preservarem suas imagens sociais. A divergência é um ato de fala ameaçador da imagem social positiva do indivíduo. Ela envolve a desaprovação e contraria nosso desejo de sermos socialmente apreciados e aprovados e, na Academia, ela parece ser mais complexa. Daí, porque necessita ser estudada. Baseamos nosso estudo na Teoria de Polidez Linguística de Brown e Levinson (1978, 1987); na concepção de face de Goffman (1967) e em alguns pressupostos da Análise da Conversação. $\mathrm{O}$ resultado mostra que os docentes se preocupam com a preservação recíproca das imagens sociais e, também, com as relações sociais e, para preservá-las, usam diferentes estratégias mitigadoras, contudo não hesitam em provar que suas ideias são as mais razoáveis e devem ser adotadas.

Palavras-chave: polidez linguística; imagem social; estratégias linguísticas; academia; divergências.

\begin{abstract}
Our aim in this study is to investigate the linguistic strategies professors use at the University to mitigate their disagreements, reach their academic and scientific interests and save each others' face. Disagreement is a threatening speech act which threatens the individual's positive face. It implies criticism, disapproval and contradicts our desire to be socially approved and appreciated. At the Academy it seems to be much more complex, hence the necessity to be studied. Our study is based on Brown and Levinson's Politeness Theory (1978, 1987); on Goffman's idea of face (1967) and on
\end{abstract}

\footnotetext{
${ }^{1}$ Estudo apresentado ao Programa de Pós-Graduação em Linguística da UFMG para a obtenção do título de Doutora em Linguística.
} 
some assumptions of Conversation Analysis. The result suggests that professors care about each other's face and also about their social relationships and, to preserve them, use different mitigating strategies, but they will not hesitate to prove that their ideas are the most reasonable and must be adopted.

Keywords: linguistic politeness; face; linguistic strategies; academy; disagreement.

\section{Introdução: concepções de polidez}

O que é polidez? Como ela pode ser definida? Como pode ser expressa nas diferentes culturas? As respostas para tais indagações são de difícil consenso, visto que envolvem valores e crenças individuais, sociais e culturais. Assim, o que é polido para um indivíduo, pode não ser para outro, para dado grupo social, ou não sê-lo para uma ou mais culturas.

Watts (2003, p.1-17) ao discutir a complexidade que envolve a noção de polidez, afirma que "os termos polido e polidez e a gama lexical de equivalentes em outras línguas pode variar nos significados e conotações a eles associados, de um grupo para outro e, até, de um indivíduo para o outro". Desse modo, a "linguagem que a pessoa usa para evitar ser muito direto", "a linguagem que demonstra respeito ou consideração pelos outros", ou, ainda, "a linguagem que expressa elocuções formulaicas" como "por favor", "obrigada", "desculpe' e "sinto muito" são alguns exemplos de interpretações leigas sobre polidez, expostos pelo autor. Para o estudioso, o caráter tanto da polidez quanto da não polidez é essencialmente avaliativo e ambas, igualmente, são locus de disputa social através de práticas discursivas.

Dhoquois (1993) por sua vez, considera a polidez tão indispensável quanto a democracia e afirma que todos os indivíduos são envolvidos pela multiplicidade de suas contradições e emaranhados pela antinomínia entre sociabilidade e espontaneidade, hipocrisia e autenticidade, boa e má educação. Esses, para a autora, são conceitos capazes de propiciarem classificações sociais definitivas entre os que sabem usá-la e os que não sabem fazê-lo. Assim, olhar nos olhos em dado lugar; evitar o olhar em outro; andar nu em um; vestirse em outro; parecer gentil em um e rude em outro são contradições 
que envolvem a diversidade dos códigos de polidez que não são possíveis nem desejáveis de serem resolvidas.

Independentemente de suas formas, a polidez, como um código de conduta em sociedade, é universal e necessária, visto que sempre houve e sempre haverá a necessidade de modos de regulamentação das relações humanas. Ao nos forçar a superar nossos reflexos de recusa, a polidez, talvez, autorize nosso encontro com o outro e, talvez, possibilite, até, o diálogo, afirma Dhoquois (op. cit). É a polidez, por meio da multiplicidade de suas formas, o primeiro sinal através do qual damos uma chance ao outro. Contudo, a autora esclarece que polidez não é conciliação e que não podemos negar a potencialidade da comunicação contida na agressividade, tampouco a agressividade implicada pelo humor, a despeito de ele situar-se no limite das boas maneiras.

Dessa forma, a polidez adquire importância no cotidiano e seu objetivo é somente tornar agradável a coexistência de indivíduos chamados a conviver, segundo a estudiosa. Cremos, porém, que mais que tornar agradável a convivência dos indivíduos, a polidez tem a função primordial de tornar possível essa convivência e conforme afirma a própria estudiosa, ela "nos forçaria a superar os nossos reflexos de recusa" e nos levaria a dar uma chance ao outro, isto é, a polidez forçando-nos à tolerância nos levaria a uma coexistência possível.

A polidez tem sido, nos últimos 25 anos, objeto de interesse de sociolinguistas, psicólogos sociais e de cientistas sociais dentre outros estudiosos. Para a Antropologia Social, por exemplo, o foco segundo Watts (2003) consiste no limite que há entre certas formas de uso da língua, como termos vocativos, honoríficos, atos de fala indiretos, expressões formulaicas e o processo de socialização e o consequente comportamento social. O estudo da polidez, para o autor, detém-se, direta ou indiretamente, na apresentação, manutenção e, até, na adequação de um conceito de "apresentação do eu" no decorrer das interações sociais, no desenvolvimento histórico de padrões culturais específicos e na distribuição de status e de poder nos grupos sociais. A polidez torna-se, portanto um tópico de interesse, não somente de pesquisadores, mas importante, também, para o cotidiano do indivíduo, uma vez que pode ser interpretada como um dos limitadores ou 
delimitadores do comportamento humano, com potencial para viabilizar uma vida social efetiva.

Conforme Brown e Levinson $(1978,1987)$ uma vez que a polidez pode ser expressa através da linguagem, descobrir os princípios de usos da língua pode ser indicativo das normas de conduta das quais a vida social, no seu aspecto interacional, é constituída, o que significa dizer que a maneira como usamos a língua pode revelar muito das relações sociais.

Dessa forma, a academia se torna um instigante locus de estudo. Sendo dialética por excelência e como o lugar que produz o conhecimento e a ciência, ela, como qualquer outro espaço social, está sujeita ao estabelecimento de relações de força e de disputas em prol do estabelecimento do que cada um dos seus agentes julga ser a concepção ideal de mundo e a teoria adequada. É ela, conforme Bourdieu (1983) um espaço de concorrência pelo estabelecimento da autoridade ou da competência científica. Assim, não é incomum a existência de antagonismos, de conflitos de ideias, de crenças, de valores e de interesses, nesse contexto. Na academia, os antagonismos se instauram, conforme Bourdieu (2003) como um processo de excomunhão recíproca dos pares para estabelecerem a ortodoxia e obterem reconhecimento. O que busca cada estudioso é estabelecer suas divisões, classificações e categorizações de mundo, através da palavra. Porém, sendo esses estudiosos, também, indivíduos sociais, de que forma conciliam seus diferentes interesses? Como fazem para atingir seus objetivos acadêmico-científicos, preservando, simultaneamente, suas imagens e relações sociais? Mediante os antagonismos de ideias, como conciliá-los com os interesses sociais de serem admirados, respeitados e benquistos? Os docentes se preocupam com o aspecto interacional das relações ou estão mais preocupados com o aspecto transacional das informações? (BROWN e YULE, 1983). Então, como manifestam suas divergências na academia? A quais estratégias linguísticas recorrem?

Portanto, neste trabalho, com base na Teoria da Polidez Linguística de Brown e Levinson (1978, 1987) e em alguns pressupostos teórico-metodológicos da Análise da Conversação de Sacks et al.(1974) e na concepção de face de Goffman (1967) investigamos como os professores expressam suas divergências em fóruns apreciativos e deliberativos da Academia, quais estratégias 
linguísticas atenuadoras usam para mitigarem o dissabor de suas divergências sobre seus interlocutores e, assim, preservarem suas imagens sociais e, consequentemente, suas relações sociais. Esses fóruns são Coordenações de Cursos, Conselho de Professores e Conselho de Centro.

Acreditamos que um estudo dessa natureza poderá nos tornar mais habilidosos quanto à nossa prática linguística, visto que um conhecimento mais aprofundado das alternativas expressivas de uma língua talvez nos leve a um melhor gerenciamento de seu uso e, consequentemente, a interações sociais mais proveitosas, uma vez que esse conhecimento poderá ser um valioso instrumento para a resolução de conflitos e equívocos, bem como para a compreensão e aceitação das diferenças linguísticas de indivíduos que não compartilham das mesmas normas culturais.

\section{A teoria da polidez linguística}

A Teoria da Polidez Linguística de Brown e Levinson (1978, 1987) é desenvolvida com base na concepção de face de Goffman (1967) para quem face é uma a imagem social que o indivíduo projeta para seus interlocutores em dada circunstância interlocutiva face a face. Desse modo, para Goffman (1967) face é:

um valor social positivo que o indivíduo efetivamente reclama para si, a partir de uma conduta que outros indivíduos compreendem que ele adotou durante um contato específico. Face é uma imagem auto-delineada em termos de atributos sociais aprovados, embora seja uma imagem partilhada com outros, como quando o indivíduo tem um bom desempenho junto ao seu trabalho ou igreja, ou a partir de um bom desempenho para si mesmo² (GOFFMAN, 1967, p.5).

\footnotetext{
2 "...the positive social value a person effectively claims for himself by the line others assume he has taken during a particular contact. Face is an image of self delineated in terms of approved social attributes- albeit an image that others may share, as when a person makes a good showing for his profession or religion by making a good showing for himself."
} 
Face é, portanto, uma imagem social, uma impressão autodelineada, aprovada socialmente e reclamada para si pelo indivíduo. Ela é um construto sagrado, o indivíduo a aprecia, com ela é comprometido, emocionalmente envolvido e realiza constantes investimentos para preservá-la e mantê-la. A imagem do outro, bem como a nossa, para Goffman, são construtos da mesma ordem, e as normas do grupo e a situação de interlocução dirão quão valiosa essa imagem é e o quanto será valorizada pelo grupo ao qual o indivíduo pertence. Essa imagem vai se delineando ao longo das interações, não é fixa, não é um rótulo e a sua preservação é uma condição da interação e não o seu fim. Assim, da maneira como o indivíduo sentese comprometido com a projeção e com a preservação desse eu social pelo qual tem apreço e sente-se envolvido emocionalmente, de igual forma, deverá sê-lo com a preservação e com a manutenção da imagem dos seus interlocutores.

As interações face a face, contudo, são situações de exposição pública, por isso, em si mesmas, ameaçadores, diz Goffman (1967). A autoimagem projetada, por sua vez, é frágil e é submetida a contínuos riscos, daí a necessidade de contínuos investimentos para sua preservação e manutenção, no decorrer das interações, uma vez que poderão ocorrer situações desabonadoras, fatos que contradigam, desacreditem ou lancem dúvida sobre ela. Dessa forma, torna-se necessário um comprometimento mútuo dos indivíduos com os trabalhos táticos, defensivos e protetores para a proteção recíproca das imagens sociais envolvidas nas interações.

Apoiados nesses pressupostos, Brown e Levinson (1978, 1987), propõem um modelo de indivíduo dotado de razão, isto é, com capacidade de desenvolver raciocínios práticos que lhe permitam adequar meios à consecução de seus fins. Esse indivíduo possui uma imagem pública, socialmente construída, na qual investe e que pode ser perdida, mantida e valorizada e a qual necessita que lhe seja dedicada contínua atenção. Tal imagem, conforme esses estudiosos, consiste de um aspecto negativo e de um aspecto positivo, ambos relacionados. $\mathrm{O}$ aspecto negativo negative face, ou imagem social negativa, diz respeito ao território íntimo, ao espaço de preservação pessoal do indivíduo o qual requer o direito de não ser destratado, que quer ter liberdade de ação, que não deseja ser submetido a imposições 
e que não deseja que suas ações sejam obstruídas por outrem. O aspecto positivo positive face, ou imagem social positiva, por sua vez, refere-se à autoimagem pública ou à personalidade a qual envolve o desejo de o indivíduo ser apreciado e aprovado pelos membros do grupo social.

Com este raciocínio, Brown e Levinson afirmam que há atos de fala que são intrinsicamente ameaçadores à imagem dos envolvidos nas interações face a face, destacando, dentre eles, os que ameaçam, primeiramente, a imagem dos ouvintes, bem como a dos interlocutores, seja essa imagem negativa seja positiva. Esses atos de fala podem ser realizados explicitamente sem mitigação (on record, baldly), explicitamente com mitigação (on record with redress), ou, ainda, de maneira indireta (off record).

Dentre os atos de fala que ameaçam a imagem negativa dos interlocutores Brown e Levinson (1978, 1987) apresentam ordens e pedidos, sugestões, alertas/avisos, coações e ameaças. Também, oferecimentos e promessas, os quais indicam comprometimento futuro do falante para com o interlocutor. Compõem esse grupo, ainda: elogios; expressões de desejo e de admiração; expressões de fortes emoções negativas, como inveja, ira e cobiça. Eles representam atos de fala ameaçadores da imagem positiva do interlocutor.

A desaprovação; as críticas; as atitudes de desdém, de desprezo ou de ridículo; as reclamações; as repreensões e censuras; as acusações e insultos; o ato de contradizer, de discordar e de desafiar o interlocutor são considerados atos de fala ameaçadores que ameaçam primeiramente a imagem positiva do interlocutor. Também as expressões de descontrole ou que possam coagir, amedrontar ou embaraçar o interlocutor; a menção de tópicos tabu; expressões irreverentes; boatos bons ou ruins sobre o interlocutor; menção de tópicos controversos, como política, religião e raça pertencem a essa categoria. A falta de cooperação deliberada; interrupção de turno; desatenção para com a fala do interlocutor e o uso de termos identificadores errados, propositadamente, ou por equívoco, também, pertence a essa primeira categoria.

Dentre os atos de fala que ameaçam, primeiramente, a imagem negativa do locutor, estão as expressões de agradecimentos; de aceitação de agradecimentos; de pedidos de desculpas pelo interlocutor; de aceitação de agradecimentos ou das desculpas do 
interlocutor; aceitação de ofertas; respostas/reações a gafes e, ainda, o comprometimento com promessas ou ofertas indesejáveis.

São considerados, por Brown e Levinson (1978, 1987), atos ameaçadores à imagem positiva do falante: os pedidos de desculpas pelo falante, o que pode indicar arrependimento por haver produzido um ato de fala ameaçador anteriormente; a aceitação de elogios; cumprimentos; desequilíbrio corporal; tropeços; quedas (não verbais) confissões; autodepreciação; o ato de contradizer-se; a admissão de culpa ou de responsabilidade por fazer ou deixar de fazer alguma coisa por desconhecimento de algo que se supunha sabido; e, ainda, a expressão de emoção e descontrole sobre o riso ou sobre as lágrimas, dentre outros.

Partindo dessa categorização de atos de fala considerados ameaçadores à imagem, seja positiva seja negativa, dos envolvidos em interações verbais face a face, Brown e Levinson $(1978,1987)$ expõem um conjunto de recursos alternativos para que os falantes produtores desses atos ameaçadores (FTAs) possam mitigá-los. Tais recursos são nomeados de estratégias de polidez positiva e de polidez negativa. $\mathrm{O}$ uso dessas estratégias é proporcional à dimensão da ameaça.

A polidez positiva, sugerida pelos estudiosos, é uma estratégia aproximativa, voltada para a valorização da imagem do interlocutor e envolve o desejo do falante de atender à necessidade de preservação da imagem positiva desse interlocutor. Ela pode ser expressa pela declaração do falante de que ele e seu interlocutor têm algo em comum, que pertencem a uma classe de pessoas que compartilham desejos comuns. Entre eles, objetivos e valores e, alguns valores e objetivos, desse interlocutor, também são importantes para o falante. $\mathrm{O}$ uso dessa estratégia não necessita, obrigatoriamente, estar relacionado à produção de um ato de fala ameaçador. Através dela, o falante demonstra que, de alguma forma, ele e seu interlocutor têm desejos coincidentes e o interlocutor é considerado um parceiro, alguém com os mesmos direitos e valores. E por isso o ato de fala ameaçador produzido não representa uma avaliação negativa de sua personalidade.

Uma das formas de expressão de polidez positiva é a demonstração do falante de que percebe interesses, necessidades e desejos do interlocutor e buscará atendê-los. Também, a expressão exagerada de interesse, de aprovação e de simpatia para com ele é uma forma de manifestação dessa forma de polidez. Compõe, ainda, esse 
grupo, o uso de marcadores grupais de identidade; o uso de dialetos ou de linguagem inter-grupais e o uso de jargões ou de gírias. A manifestação dessa polidez pode se dar, ainda, pela busca de formas amenas ou adequadas de discordar. Assim, em vez de discordar através de um categórico "não", o falante buscará primeiramente o ponto consensual. A ironia, ou, ainda, a simulação de chegada a uma conclusão com base em um raciocínio supostamente desenvolvido em conjunto, sem que, realmente, falante e interlocutor tenham realizado uma negociação anterior, é uma das formas de manifestação de polidez positiva. A pressuposição de conhecimento comum expressa através do tempo e do esforço despendidos por um falante com um interlocutor conversando tópicos avulsos; o uso da imprecisão seja através do eufemismo seja da hipérbole; o uso de termos no extremo de uma escala para mais ou para menos para suavizar uma crítica ou reclamação e, também, a demonstração de que o falante conhece as necessidades e atitudes do interlocutor e de que compartilham os mesmos valores são formas de sinalização de polidez positiva. Também o são: o uso de piadas e brincadeiras para deixar o interlocutor à vontade; a realização de ofertas e promessas, embora insinceras, indicadoras de que os desejos do interlocutor e do falante são os mesmos e de que este falante ajudará o interlocutor a atingí-los; a implicitação de que falante e interlocutor estão numa atividade cooperativa.

Além da assunção de comportamento otimista em relação ao fato de que o interlocutor tem os mesmos desejos que o falante, isto é, coopera com ele e que o ajudará a realizar os seus objetivos; da inclusão do falante e do interlocutor numa atividade, através do inclusivo nós, quando o falante quer dizer tu/você; do fornecimento de explicações que justifiquem o desejo do falante e que tentam incluir o interlocutor no raciocínio deste falante, levando-o a assumir a reciprocidade de objetivos; do destaque aos direitos e hábitos recíprocos de falante e ouvinte de se dirigirem atos de fala ameaçadores, todas essas são formas de expressão da polidez positiva.

A polidez negativa, por outro lado, é definida, por Brown e Levinson $(1978,1987)$ como uma forma de estratégia reparadora direcionada à imagem negativa do interlocutor, ao seu desejo de não ter suas ações obstruídas, de não ser pressionado e de ter liberdade de agir conforme sua escolha. Esta é uma estratégia de distanciamento e é 
expressa pelo uso de marcadores formais de polidez; marcadores de deferência e com o uso de amenizadores de imposição. Sua função, conforme os estudiosos, é minimizar a imposição peculiar que o ato de fala ameaçador, inevitavelmente, realiza e envolve tanto a transmissão explícita do ato de fala ameaçador (FTA) quanto o reparo deste.

Assim, a polidez negativa pode ser expressa pelo uso de termos ou de palavras que mudem a força do enunciado, tornando-o vago, impreciso ou parcial; também, por circunlóquios; pela violação das máximas de Grice (1975); através da prosódia e da cinésica; através da expressão explícita de dúvida sobre o resultado do ato de fala do locutor, dada a condição de pertinência de produção desse ato.

A demonstração de deferência, sinalizando o reconhecimento do interlocutor à relativa imunização e à inexistência de condição/direitos do locutor de coagir seu interlocutor é, também, uma das formas de manifestação de polidez negativa. Faz, também, parte do conjunto de manifestações de estratégias dessa forma de polidez, a apresentação de desculpas pela realização do ato de fala ameaçador (FTA). O temor dessa produção, por sua vez, pode ser indicado pelo uso deferente de hesitações; pela admissão da ofensa; por demonstração de relutância, por meio de evasivas e de rodeios; pelo pedido de perdão e pela apresentação de motivos superiores. A impersonalização, também, é uma forma de expressão da polidez negativa. Ela pode ser realizada com a omissão dos pronomes $t u / v o c \hat{e}$, sujeito dos verbos na forma imperativa; pelo apagamento do pronome oblíquo em formais verbais que implicam intrínsecos atos de fala ameaçadores, como "isto parece-(me"); pelo uso do pronome de $2^{\text {a }}$ pessoa de plural "vocês" para fazer referência a um único destinatário, uso comum em várias línguas e culturas, servindo para indicar poder ou distância e, ainda, pela enunciação do ato de fala ameaçador (FTA) como se este fosse decorrente de uma regra social geral, de regulamento ou obrigação, o que permite ao interlocutor dissociar-se da imposição específica do ato de fala ameaçador. Também, a distinção realizada entre o sujeito e sua profissão, cargo ou ofício que exerce; a manipulação do tempo, quando é trocado o presente pelo passado e o locutor se autodistancia do "aqui" e do "agora", são formas de manifestação da polidez negativa. A nominalização e, ainda, a expressão explícita, seja do comprometimento seja do descomprometimento do locutor para com o interlocutor no que se 
refere a favores, deveres e responsabilidades e, ainda, o uso de formas passivas como meio de evitar a referência às pessoas envolvidas na produção do ato de fala ameaçador (FTA) são formas de essa polidez ser expressa.

\section{Metodologia}

\subsection{O corpus}

O corpus da pesquisa é constituído da transcrição de vinte horas de gravações de reuniões de instâncias apreciativas e deliberativas da administração intermediária e da administração básica de uma das universidades públicas para as quais solicitamos autorização para gravarmos os eventos. Tais instâncias são Coordenações de Cursos, Conselho de Centro e Conselho de Professores. As gravações, por sua vez, foram realizadas no decorrer de cinco meses dos anos de 2004 e 2005.

\subsection{A convenção}

As gravações dos eventos foram transcritas com base na convenção sugerida por Sacks et al. (1974) e por Marchuschi (1991), porém obedecemos ao sistema padrão da escrita ortográfica e buscamos manter fidelidade à real produção dos falantes, excetuando quando esta produção se apresentava de forma singular, podendo ser significativa para o estudo. A seguir, alguns dos sinais da convenção utilizada:

1. [[ - falas simultâneas: dois colchetes duplos serão utilizados, no início de um turno, quando dois falantes iniciam um turno ao mesmo tempo;

2. [ - simultaneidade de: um colchete simples abrindo será utilizado quando ocorrer uma simultaneidade de vozes que não se dá desde o início do turno e, sim, a partir de um certo ponto;

3. [ ] - sobreposições localizadas: quando uma sobreposição de vozes ocorre em dado ponto de um turno e não forma novo turno usamos um colchete abrindo e outro fechando; 
4. (+) - pausas: as pausas e silêncios são indicados entre parênteses, sendo utilizado um sinal de mais $(+)$ para pausas pequenas e (++) para pausas mais longas;

5. ( ) - dúvidas e suposições: as dúvidas e suposições são marcadas com parênteses, usando-se a expressão incompreensível no seu interior, ou aí escrevendo-se o que supostamente foi ouvido;

6. -/- truncamentos bruscos: quando um falante corta uma unidade, o fato é marcado com uma barra oblíqua, o mesmo ocorrendo quando alguém é bruscamente interrompido por seu interlocutor;

7. maiúsculas - ênfase ou acento forte: maiúsculas são usadas quando uma sílaba ou palavra é pronunciada com ênfase ou recebe acento mais forte que o habitual;

8. :: - alongamento de vogal: o alongamento de vogal é indicado com dois pontos, os quais podem ser repetidos, dependendo da duração e do alongamento;

9. (( )) - parênteses duplos: os parênteses duplos são utilizados quando são feitos comentários sobre algo, logo após o local da ocorrência ou imediatamente antes do segmento a que se refere, podendo, ainda, serem colocados entre um turno e outro;

10. - (hífen) - silabação; o hífen é utilizado para indicar a ocorrência de palavras pronunciadas silabadamente;

11. repetições: eeee ele; ca ca cada - são reduplicadas as letras ou sílabas para indicar as repetições:

12. pausa preenchida, hesitação ou sinais de atenção - são usados basicamente a reprodução de sons cujas grafias estão mais ou menos claras como: $e h$, ah, oh, ih; mhm; ahã, entre outros;

13. transcrição parcial ou eliminação: ... - para a indicação de transcrição parcial ou eliminação de falas são usadas reticências no início e no final de uma transcrição, para ser indicado que está sendo transcrito apenas um trecho da gravação. Por sua vez, as reticências entre duas barras /.../são usadas para indicar que houve um corte na produção de alguém; 
14. identificação dos interlocutores e das instituições envolvidas - com o fim de preservar a identidade dos participantes das interações linguísticas, as identificações são feitas através de nomes fictícios, o mesmo ocorrendo em relação à instituição envolvida;

15. ortografia de nomes próprios - para melhor entendimento dos dados, adotamos, também, como convenção grafar os nomes próprios, seja de pessoas, seja de instituições ou siglas, nas interações, em letras minúsculas para não serem confundidos com a ênfase prosódica das palavras que são grafadas, conforme a convenção adotada, em maiúsculas.

\subsection{A identificação das divergências}

Para a identificação e análise das divergências nas interações docentes, reestruturamos o modelo sugerido por Kangashsarju (2002) para essas ocorrências linguísticas, o qual adquire a seguinte estrutura:

A: Asserção do falante, primeira parte do par adjacente;

B: Divergência do falante, segunda parte do par adjacente;

A: Defesa do ponto de vista do falante, primeira parte do par adjacente; reforço deste e manutenção da ideia exposta anteriormente.

B: Reforço da divergência do falante, segunda parte do par adjacente.

C: Aquiescência de um dos falantes; abandono do seu ponto de vista em prol de outro; ou abandono de tópico sem elucidação da divergência.

Dessa forma, buscamos nas interações:

1. os pares adjacentes: proposição/divergência;

2. o ponto de vista contido na asserção do falante, primeira parte do par adjacente e gerador da divergência;

3. a expressão de divergências explícitas com, ou sem, mitigação pelo falante, segunda parte do par adjacente,

4. a defesa do ponto de vista do falante, primeira parte do par adjacente; reforço e manutenção de seu ponto de vista; 
5. aquiescência de um dos falantes; abandono de seu ponto de vista e elucidação da divergência ou abandono de tópico sem elucidação do antagonismo.

\section{Análise e discussão dos dados}

Nesta análise, apresentamos algumas das estratégias utilizadas pelas falantes da interação para mitigarem a expressão de suas divergências. No excerto 1. (319/349), de uma das reuniões de Conselho de professores, eles discutem as alterações que devem ser feitas na nova proposta pedagógica de um dos cursos da Faculdade de Ciências Humanas da Universidade. Essa proposta deverá ser submetida à apreciação dos colegiados superiores de Ensino Pesquisa e Extensão-CEPE e ao Conselho Universitário-CONSU, para aprovação. A divergência ocorre porque uma das idealizadoras da proposta considera uma das alterações sugeridas, referente à distribuição das atividades acadêmicas pela quantidade de horas/aula, no projeto, desnecessária.

\section{Excerto 1}

319.Sheila. por que foi que nós colocamos trezentos e sessenta horas e não e 320.não quatrocentas? por causa do número de créditos. isso aí .já foi uma 321. conta e nossa conta não DA:va porque a gente ainda raciocina MUI:to, 322.aliás foi uma co/ foi uma coisa muito difícil achar o/a nossa conversa 323.com prograd porque nós raciocinamos em CRÉdito e a prograd em horas, 324.então foi muito diFícil nos adaptarmos à resolução, então então essa foi a, 325.a: a solução, a saída que nós encontramos pra essas trezentas e sessenta 326.horas, certo(+)por que que fica difícil a gente pensar em operacionalizar 327.um currículo(+)POR:QUE POR:que a gente sóPEN:sa(+)no currículo 328.como presencial(+)não é, e essas questões .que são da vida acadêmica, 329.que são participações em pesquisa, participações em,em,em conGRES:so, 330.apresentação/que tem MUItos alunos de letras já envolvidos NISso. tem 331.alunos de letras que SA:EM diREto do curso de letras, por causa dessas 332.atividades complementares, principalmente/saem diREto para o 333.mesTRAdo.nós temos casos e mais casos, nós temos de/e/que/eu acho 334.que de .TRIN:ta, de trinta e tantos ou de cinqüenta e tantas pessoas do, 335.do, mestrado em lingüística aplicada, atualmente, VINte 336.saí:ram(+)diretamente da graduação,certo(+)por conta disso.aí a gente 
337.quis/isso que a gente tá fazendo no cuRRÍ:culo(+)atual né, nesse caso que 338.tá em voga fazendo sem ele levar CRÉdito, então a gente queRI:a que 339.isso, não é, que isso juntassem as coisas, não é(+)então eu achei bastante 340.interessante aquela sugestão ali, não é(+)de/da gente/que eu acho que não 341.precisaria NEM a gente fazer ajuste nenhum porque, porque $\mathrm{o}, \mathrm{o}, \mathrm{o}$ 342.projeto ele .nã:o/ele só/ele só não diz/não é(+)mas a gente pode dentro 343.aqui de uma reunião de departamento dizer, olha, TANtas horas vão ser 344.pra isso e tantas ho:ras vão ser.pra aquilo, não é(+)e inclusive eu estava 345.vendo a resolução que não está no projeto, mas ele conta como atividade 346.científico-cultural o aluno assistir a pa/a,a, a palestra, obrigada, que nós

Léa:[palestra, palestra.] [de nada]

347.não tínhamos previsto/nós tínhamos previsto só ele, ele 348.apresentando/ele,ele,ele,ele propondo resumo, não é(+)então, então, 349.então, ISso/a,a,a/mas ISso TAMBÉM o projeto/ ISso TAMBÉM o 350.projeto a, a/ então, não vai, não vai de encontro ao que está no projeto não é?

351.Rosa: não, não, não vai. o único problema, sheila, é que nós temos que 352.ver o, o seguinte(+)na HO:ra que for contabilizar, olha lá, quando o mec 353.exige oitoCENtas horas de PRÁtica, se você mistura a PRÁtica com as 354.atividades acadêmico-científicas aí é que tá o problema.nós só 355.queremos(+)aqui(+)SÓ: fazer essa peQUEna modificação de 356.DIStribuiÇÃO que o proJEto, que .o projeto não distribui pra gente poder 357.colocar/fazer um aditivo, mandar para o.mec pra ficar Tudo de acordo 358.com a determinação do MEC.é só uma questãozinha de distribuição. $o$ 359.projeto está maraviLHO:SO. nós só precisamos fazer esse 360.pequeno ajustezinho matemático pra evitar problema. pra que dePOIS 361.não venham trazer problema pra nós.

362. Sheila:eu só tô achando estranho porque esse projeto passou pelo 363.conselho, passou por um parecerista...e ela disse que estava dentro das 364.especificações TÉCnicas.

$\mathrm{Na}$ interação, Sheila, uma das idealizadoras da proposta pedagógica em discussão, expõe como distribuíram trezentos e sessenta das quatrocentas horas que deveriam ser divididas entre as atividades acadêmicas no projeto. A falante defende que, além de não precisarem alterar o projeto, ainda, poderiam definir como usar as quarenta horas que faltam distribuir numa reunião de departamento. Diz ela (1. 339/350): "então eu achei bastante interessante aquela sugestão ali, não é(+)delda gentel_que eu acho que não precisaria NEM a gente fazer ajuste nenhum porque, porque o, o, o projeto ele 
nã:olele sólele só não dizl não é(+) mas a gente pode dentro aqui de uma reunião de departamento dizer, olha, TANtas horas vão ser pra isso e tantas ho:ras vão ser pra aquilo, não é?". Depois, ela explica que o projeto prevê como atividade científico-cultural o aluno assistir a palestras, porém haviam colocado apenas a apresentação de resumos e indaga se esta proposta se opõe ao que consta no documento. Depois, busca a confirmação do grupo com a interrogativa posposta, não é. Diz ela (1. 347/350): "nós tínhamos previsto só ele, ele apresentando/ ele,ele,ele, ele propondo resumo, não é(+) então, então, então, ISso/a, a, al mas ISso TAMBÉM o projeto a, a/ então, não vai, não vai de encontro ao que está no projeto, não é ?". O pressuposto contido na pergunta é o de que este seria o único ponto que poderia estar errado e contrariar objetivo do documento, mas se isso não ocorre a proposta está adequada.

Jacobs (1989:34 apud Walton 1990:341-343) discutindo falhas e falácias do ato de perguntar, chama a atenção para alguns tipos de perguntas as quais, funcionando como atos de fala indiretos, são, de fato, asserções e, portanto, nada havendo para responder ou de incerto com elas. Tais asserções, cujo objetivo é levar o interrogado a se comprometer, são usadas na forma interrogativa como tática de ataque argumentativo e, devido à sutileza com a qual são estruturadas, podem levá-lo à derrota, porque, dependendo de sua natureza, o interrogado poderá fazer concessões nocivas a si, tornando-se extremamente vulnerável.

Dessa forma, com esta indagação, Sheila deseja demonstrar que se a atividade proposta não se contrapõe ao que consta no projeto, então, nada há de errado com ele. Sua pergunta, uma interrogativa negativa, é elaborada para receber uma resposta negativa, que atenda ao seu propósito, o que, de fato, ocorre.

Rosa, sua interlocutora e antagonista, responde-lhe negativamente, atendendo à sua expectativa. Diz Rosa (1. 351): "(não), (não), não vai". A resposta é expressa por um enunciado contendo, apenas, o advérbio de negação "não", enfatizado pela repetição do mesmo advérbio e, ainda, por um enunciado afirmativo negativo "não vai".

A falante, conforme preceituam Brown e Levinson (1978, 1987) evita o desacordo imediato. Então, usando uma estratégia de polidez positiva, "evitar a discórdia” (avoid disagreement), 
primeiramente, ela busca o ponto consensual, possivelmente, tentando minimizar o constrangimento para Sheila (LEECH, 1983) e preservar sua imagem positiva.

Contudo, logo depois, a falante/antagonista apresenta o ponto incongruente do trabalho e reafirma a necessidade de alterarem-no e, dessa maneira, se instaura a divergência de pontos de vista, uma vez que Sheila afirma que não há necessidade de mudá-lo. Afirma Rosa (1.350/357): "o único problema, sheila ...se você mistura a PRÁtica com as atividades científico-culturais aí é que tá o problema. nós só queremos aqui Só fazer essa pequena modificação...para poder mandar para o mec pra ficar TU:do de conformidade como que o mec colocou...é só uma questãozinha de distribuição." Rosa não diz claramente que o documento está errado. Ela procura uma forma amena de dizê-lo, afirmando que a indistinção entre a atividade de prática e as atividades científico-culturais constitui um "problema", daí a necessidade de mudarem. Embora o termo problema possa ter uma acepção pejorativa, tem um caráter mais geral, é mais inespecífico que o adjetivo "errado". Dessa forma, a escolha desse item lexical pode demonstrar uma tentativa de Rosa de não ser tão categórica na sua avaliação e evitar o constrangimento para Sheila.

Essa tentativa de atenuação pode ser observada ao longo de todo o seu pronunciamento. Além de evitar dizer que o documento está errado, ela, ainda, afirma que é o "único problema". Com o uso do adjetivo exclusivo "único", ela descarta a possibilidade de haver outras inadequações, concorrendo, desse modo, para a manutenção da imagem positiva de Sheila, conforme Brown e Levinson $(1978,1987)$. Depois, por meio do advérbio "só", usado duplamente na expressão (1.354/356): "nós só queremos aqui SÓ fazer essa pequena modificação...", Rosa exclui a possibilidade de outras alterações e restringe o desejo do grupo a, apenas, ao que ela define de "pequena modificação". Então, o grupo quer: "SÓ fazer a pequena modificação". A falante usando o adjetivo "pequena" minimiza a extensão da mudança a ser realizada. Essa é uma estratégia de polidez positiva de valorização da imagem do outro: a estratégia de generosidade (gift giving). Para fazer a alteração parecer mínima ou insignificante, Rosa concorre para a proteção e preservação da imagem positiva de Sheila, visto que à proporção que desvaloriza o grau ou extensão das modificações a serem realizadas mais ressalta a adequação do 
documento e, consequentemente, torna mais visível o nível de acerto de seus idealizadores. Dessa forma, Sheila, como representante do grupo, tem sua imagem positiva valorizada e mantida.

A atitude de busca de valorização da imagem positiva de Sheila se repete quando Rosa afirma (1. 358): “é só uma questãozinha de distribuição". Nesta afirmação, através de uma alteração morfológica no termo "questão", ao qual ela acrescenta o sufixo diminutivo "inha", dizendo ser uma "questãozinha de distribuição", a falante ratifica sua tentativa de minimizar ou desvalorizar a natureza da alteração a ser feita.

Para Caffi (2007) o sufixo diminutivo é a principal estratégia morfológica mitigadora e seu uso, neste contexto, proporcionalmente, concorre para a valorização da imagem positiva de Sheila, visto que esta classificação de "questãozinha" desvaloriza a natureza da modificação do documento tenha ela a complexidade ou dimensão que tiver enquanto o grau de acerto do documento é, novamente, posto em evidência.

Continuando sua tentativa de convencer Sheila da necessidade de alterarem o projeto, Rosa busca, concomitantemente, valorizar e manter a imagem positiva desta, através de uma estratégia de polidez positiva, gift giving, a qual é expressa pela forma positiva e hiperbólica de qualificar o trabalho realizado. Então, afirma (1. 358/359): o projeto está maraviLHO:SO. (BROWN; LEVINSON, 1978, 1987). Esta avaliação hiperbólica é reforçada, ainda, pela ênfase prosódica a qual, usada sobre a sílaba $L H O$ do adjetivo maravilhoso, sílaba essa, já tônica, e estendida à sílaba pós-tonica $S O$, dá-lhes maior proeminência.

Porém, depois de qualificar o documento enfaticamente, Rosa reafirma a necessidade de alterá-lo, dizendo que precisa fazer esse pequeno ajustezinho matemático pra evitar problema (1.360/361). Aqui, através do uso pleonástico pequeno ajustezinho, a locutora, novamente, minimiza o grau da mudança a ser realizada no projeto, o que, mais uma vez, reforça, proporcionalmente, a valorização da imagem positiva dos envolvidos no trabalho, especialmente de Sheila, representante do grupo, nesta circunstância.

Continuando, Rosa, acrescenta que para poder mandar para o Ministério da Educação, o documento deverá estar conforme o que determina essa instituição. Afirma, ela (1.343/344): "pra gente poder mandar para o mec pra ficar TU:do de conformidade com o que o mec 
colocou que é exataMENte distribuir essa carga...”. Neste trecho da interação, verificamos que Rosa pressiona Sheila, porém isenta-se da realização desse ato de fala ameaçador. Ela afirma que o documento só poderá ir ao MEC se atender às determinações dessa instituição. Logo, se o documento não for alterado não poderá ser encaminhado, o que implica que deverão alterá-lo sob pena de haver danos para todos. Rosa apoia-se na instituição para afirmar que o documento tem que ser alterado. Não é ela quem o determina, mas o MEC. Dessa forma, ela ameaça à imagem negativa de Sheila. Ela interfere no seu eixo acional, no seu desejo de não ter suas ações determinadas por outrem, porém o faz isentando-se do ato de fala ameaçador, para o que usa uma estratégia de polidez negativa, isto é, uma estratégia de distanciamento. Ela pressiona sua interlocutora baseando-se numa norma institucional a qual todos devem acatar.

Sheila, por sua vez, não aceita as observações e contraargumenta baseando-se no que Breton (2003) chama de argumento de competência, o qual pressupõe uma competência científica, técnica, moral ou profissional, prévia que legitima a avaliação que deriva desse saber. Assim, ela retruca apresentando o posicionamento dos grupos autorizados, isto é, revestidos de competência que analisaram o documento e que o acharam adequado, como o Conselho de Ensino Pesquisa e Extensão e a parecerista designada para analisar o projeto. Ela diz (1.362/364): "eu só tô achando estranho porque esse projeto passou pelo conselho, passou por um parecerista...e ela disse que estava dentro das especificações TÉCnicas". Sheila não afirma categoricamente que as observações de Rosa estão erradas ou que não as aceita e, sim, declara que acha estranho o fato de o projeto haver passado por essas instâncias abalizadas e elas não o terem questionado e, ainda, o fato de a parecerista tê-lo considerado de acordo com as especificações técnicas.

Essa forma não categórica de se expressar, usando o hedge 'achar' 'só acho estranho', se configura conforme Brown e Levinson (1978, 1987) uma técnica de polidez positiva. A falante atenua o grau de certeza do conteúdo proposicional de seu enunciado para não parecer impositiva a sua interlocutora e, assim, atenuar a ameaça à imagem positiva desta.

Para Eemeren et. al. (2002) a confissão de um sentimento de estranheza representa uma maneira cuidadosa de se contrapor. 
Expressando dúvida ou estranhamento, Sheila demonstra que não concorda com o que está sendo dito, embora não discorde explicitamente. Rosa, por seu turno, insistindo na necessidade da alteração do documento, procura justificar sua discordância, fazendo parecer que está agindo em defesa de interesses comuns. Então, diz (1. 360/361): "pra que dePOIS não venham trazer problema pra nós." Essa uma estratégia de polidez positiva, através da qual a falante sugere que são indivíduos que compartilham interesses e objetivos comuns e que está buscando atendê-los, no caso, está tentando evitar que Sheila tenha problemas, logo, está buscando o bem de todos. Contudo, esta forma de agir pode sugerir, também, um exercício de pressão off record. A locutora pressiona, mas se isenta da responsabilidade do ato de fala ameaçador, uma vez que a dubiedade do enunciado permite-lhe isentar-se dessa responsabilidade. Assim, a falante preserva a imagem positiva de sua interlocutora e a própria imagem positiva.

Observamos, na interação, que a falante, Rosa, ao tentar convencer sua interlocutora Sheila de que o projeto tem que ser mudado, usa diferentes estratégias mitigadoras para atenuar os efeitos da divergência sobre a imagem social positiva desta. A divergência, segundo Brown e Levinson $(1978,1987)$ é um ato de fala eminentemente ameaçador da imagem positiva do interlocutor, visto que traz subjacente a desaprovação, a compreensão de que ele está equivocado em relação algo, o que envolve a ameaça de ele não ter suas ações aprovadas socialmente. Daí, porque representa uma ameaça a sua imagem positiva.

Por sua vez, o uso de diferentes estratégias mitigadoras, segundo Caffi (2007) cria um reforço sinergético da mitigação as quais, somando-se, reforçam os resultados finais, desencadeando resultados mitigadores adicionais no nível metacomunicativo. Tais resultados mitigadores adicionais, por sua vez, definem as relações e são instrumentos para moldar as imagens tanto do falante quanto do interlocutor. Para a autora, o uso de diferentes recursos mitigadores pode ser indicador do nível de apreço dos falantes para com o interlocutor, do cuidado que ele tem de manutenção da imagem positiva deste, podendo ser revelador do seu cuidado para com o caráter relacional da interação. 
Assim, podemos afirmar que Rosa demonstra esse cuidado para com a manutenção da imagem social positiva de Sheila, bem como da necessidade de preservação do elo social. Ela sabe que o projeto deverá ser modificado, sabe que o colegiado tem autonomia para alterá-lo sem a aquiescência dos seus idealizadores, contudo, tenta primeiramente convencer Sheila, uma das componentes da equipe responsável pela elaboração do documento, da inconsistência entre o que exige o MEC e o que foi realizado e, por isso, a necessidade de modificá-lo. Essa atitude pode revelar o grau de apreço dessa falante para com sua interlocutora ou o seu cuidado para com a imagem positiva desta, o que pode ser indicativo do seu cuidado para com o caráter relacional da interação.

A esse trabalho Locher (2004, p. 57) chama de "relational work: processo de definir as relações nas interações e que consiste amplamente em considerar a importância de preservação da imagem dos interlocutores, a qual, por sua vez, estará ligada ao contexto de uma dada interação". ${ }^{3}$ Para Watts (2004) este não é, apenas, um comportamento polido, mas, também, um comportamento político. Cabe ressaltar, porém, que a despeito das estratégias utilizadas pela falante para mitigar a discordância entre si e sua interlocutora, somente esta interlocutora poderá dizer ou demonstrar os efeitos do uso de tais estratégias, somente ela poderá demonstrar verbalmente ou não, se a falante/antagonista atingiu o seu intento.

\section{Considerações finais}

O objetivo do estudo foi verificar como os docentes expressam suas divergências na academia, quais estratégias usam com o intuito de conciliar interesses acadêmico-científicos e preservar a imagem social de seus pares, bem como a própria imagem social e, também, suas relações sociais.

Constatamos que os professores demonstram preocupação com a forma de expressarem seus pontos de vista divergentes. Desse modo, recorrem a diversas estratégias mitigadoras com o fim de amenizar o

\footnotetext{
3 - Relational work consists to a great extent of paying respect to face considerations, which in turn will be linked to the context of the specific interaction in question.
} 
dissabor que as divergências podem propiciar aos seus interlocutores e, assim, preservar a imagem positiva destes, bem como, a própria imagem positiva e, consequentemente, suas relações sociais. Dentre os recursos mitigadores usados pelos docentes foram identificados: a busca pelo consenso ao invés do desacordo imediato; o uso do pronome inclusivo "nós" mesmo quando o alvo de fala ameaçador é um indivíduo específico; o uso do pronome "você" de forma geral, inespecífica; o uso de marcadores de identidade grupal, como "pessoal", "colega", "gente", dentre outros, como tática aproximativa; o uso de avaliações positivas com o fim de atender o desejo de aprovação dos interlocutores, bem como o uso de evasivas e circunlóquios (hedges).

Também, foi identificado o uso da impersonalização, da personificação e, ainda, da apassivação. A indiretividade, representada por expressões de dúvida, de estranhamento, por aconselhamento e por indagações, também, foram recursos usados pelos docentes em suas interações para atenuar suas divergências.

Constatamos, porém, que apesar das diferentes estratégias mitigadoras usadas por esses falantes, eles não hesitam em demonstrar o quanto seus pontos de vista são os razoáveis e que, por isso, devem ser adotados, resultando daí, o uso de elementos que podem referendar a ameaça à imagem positiva, bem como à imagem negativa dos locutores cujos pontos de vista são objetados.

Outra constatação viabilizada pelo estudo foi a de que as estratégias mitigadoras usadas pelos professores, normalmente, são multifuncionais, isto é, elas podem beneficiar tanto ao falante cujo ponto de vista foi objetado quanto ao seu antagonista, visto que à proporção que esse antagonista demonstra ser alguém que se preocupa com o desejo e necessidade de manutenção da imagem positiva de seu interlocutor e busca atender a esse desejo concorre para a valorização e preservação de sua própria imagem social positiva.

Outra observação que o estudo nos propiciou foi a de que o conceito de face, no contexto acadêmico, pode ser mais complexo do que o sugerido por Brown e Levinson $(1978,1987)$ especialmente, o de positive face. A imagem social positiva, na Academia, parece não envolver, apenas, o desejo do indivíduo de que sua autoimagem seja apreciada e aprovada. A concepção de face, na Academia, parece mais complexa, o que implica outros valores além do desejo de o indivíduo 
ser aprovado socialmente, talvez, aproximando-se mais das concepções chinesas contidas nos termos mianzi e lian, ou seja, de dignidade ou prestígio, de mérito ou de reputação e de respeito de outros indivíduos. Assim, em decorrência dos valores que podem envolver tanto a divergência na Academia quanto a concepção de face esses são assuntos que requerem mais estudos para que suas peculiaridades, neste contexto específico, possam ser apreendidas com mais propriedade.

Quanto à polidez linguística, esse é um estudo que, conforme Watts et. al. (2005), direta ou indiretamente, detém-se na apresentação, manutenção e até na adequação de um conceito de "apresentação do eu" no decorrer das interações sociais. Seu principal objetivo é investigar como os indivíduos gerenciam suas relações interpessoais para atingir objetivos pessoais e coletivos. Podendo ser expressa por meio da linguagem, a polidez pode revelar muito da essência dos falantes de uma língua, bem como refletir muito da constituição das estruturas sociais. Logo, esta é uma investigação que poderá nos fornecer mais conhecimento sobre as diferentes nuances de uma língua, suas possibilidades expressivas e, consequentemente, mais gerenciamento e habilidade quanto ao uso do idioma. Esse conhecimento, por sua vez, poderá nos tornar mais aptos ao trânsito social, à consecução de nossos objetivos, à resolução de conflitos e, possivelmente, a relações sociais mais exitosas.

\section{Referências}

AUSTIN, John L. How to do things with words. Oxford: Oxford University Press, 1962.

BROWN, Gillian; YULE, George. Discourse analysis. Cambridge: Cambridge University Press, 1983.

BOURDIEU, Pierre. A economia das trocas simbólicas. MICELI, Sérgio (Org.). 6 ed. São Paulo: Perspectiva, 2003.

BOURDIEU, Pierre. Sociologia. ORTIZ, Renato. (Org.). Tradução de Paula Montero e Alicia Auzmendi. São Paulo: Ática, 1983. 
BROWN, Penelope; LEVINSON, Stephen. Universals in language usage: politeness phenomena. In: GOODY, Esther N. (Ed.). Questions and politeness: strategies in social interaction. New York: Cambridge University Press, 1978. p. 56-289.

BROWN, Penelope; LEVINSON, Stephen. Universals in language usage: politeness phenomena. Cambridge: Cambridge University Press, 1987.

DHOQUOIS, Regine. A polidez: virtude das aparências. Tradução de Moacyr Gomes Jr. Porto Alegre: L\&PM, 1983.

GOFFMAN, Erving. A representação do eu na vida cotidiana. Tradução de Maria Cecília S. Raposo. Petrópolis: Vozes, 1975.

GU, Yueguo. Politeness phenomena in modern Chinese. Journal of Pragmatics, v. 14, n. 2, p. 237-257, 1990.

- Interaction ritual: essays on face to face behavior: Harmondsworth: Penguin, 1967.

LEECH, Geoffrey N. Principles of pragmatics. London/New York: Longman, 1983.

LOCHER. Miriam A. Power and politeness in action: disagreement in oral communication. Berlin/New York: Walter de Gruyter, 2004.

MARCUSCHI, Luiz Antônio. Análise da conversação. 2ed. São Paulo: Ática, 1981.

SACKS, Harvey et al. A simplest systematic for the organization of turn-taking in conversation. Language, v. 50, n. 4, p. 696-735, 1974.

SEARLE, John R. Speech acts. Cambridge: Cambridge University Press, 1969. 
Verbena Lúcia Medeiros Costa

Recebido em: 15/09/2011 Aceito em: $\quad$ 25/05/2012

Title: Disagreement at the Academy: discursive strategies to protect and save speakers' face 
A divergência na academia: estratégias discursivas 